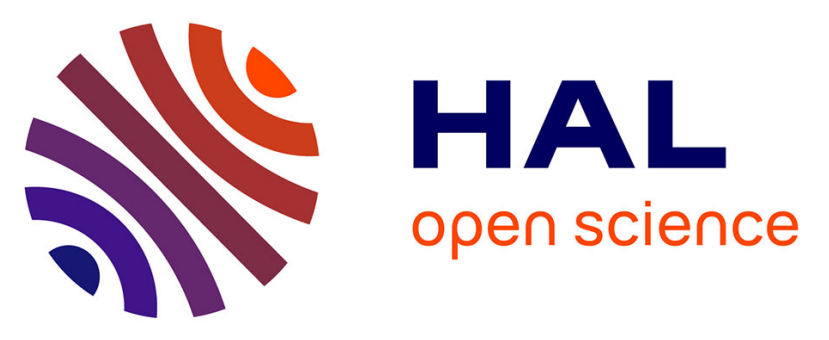

\title{
Transient stability of power systems with embedded VSC-HVDC links: Stability margins analysis and Control
}

Juan Carlos Gonzalez-Torres, Gilney Damm, Valentin Costan, Abdelkrim Benchaib, Françoise Lamnabhi-Lagarrigue

\section{To cite this version:}

Juan Carlos Gonzalez-Torres, Gilney Damm, Valentin Costan, Abdelkrim Benchaib, Françoise Lamnabhi-Lagarrigue. Transient stability of power systems with embedded VSC-HVDC links: Stability margins analysis and Control. IET Generation, Transmission and Distribution, 2020, 14 (17), pp.3377 - 3388. 10.1049/iet-gtd.2019.1074 . hal-02923391

\section{HAL Id: hal-02923391 \\ https://hal-centralesupelec.archives-ouvertes.fr/hal-02923391}

Submitted on 27 Aug 2020

HAL is a multi-disciplinary open access archive for the deposit and dissemination of scientific research documents, whether they are published or not. The documents may come from teaching and research institutions in France or abroad, or from public or private research centers.
L'archive ouverte pluridisciplinaire HAL, est destinée au dépôt et à la diffusion de documents scientifiques de niveau recherche, publiés ou non, émanant des établissements d'enseignement et de recherche français ou étrangers, des laboratoires publics ou privés. 


\title{
Transient stability of power systems with embedded VSC-HVDC links: Stability margins analysis and Control
}

\author{
Juan Carlos Gonzalez-Torres ${ }^{1}$, Gilney Damm², Valentin Costan ${ }^{3}$, Abdelkrim Benchaib ${ }^{1}$, Françoise \\ Lamnabhi-Lagarrigue ${ }^{2}$ \\ ${ }^{1}$ SuperGrid Institute, 69100 Villeurbane, France \\ ${ }^{2}$ Laboratoire des signaux et systèmes (L2S), 91190 Gif-surYvette, France \\ ${ }^{3}$ EDF Lab Paris-Saclay, 91120 Palaiseau, France \\ *E-mail: juan-carlos.gonzalez@supergrid-institute.com
}

\begin{abstract}
This paper investigates the impact of embedded Voltage Source Converter-based High Voltage Direct Current (VSCHVDC) links on AC grids transient stability. Firstly, using Transient Energy Functions (TEF), it is demonstrated that VSC-HVDC links controlled to track constant power references, do not inherently improve transient stability of the surrounding AC grid as an AC line naturally does. Then, a control law using the feedback linearization technique on a simple but representative power system is derived. The control law highlights and combines the three main actions the VSC-HVDC link can offer to enhance rotor angle stability: fast power reallocation, injection of synchronising power and injection of damping power. The control law is implemented and validated in EMT simulation. It is then shown that an HVDC link can assure the synchronisation of different AC areas even if no AC transmission lines interconnect them. Through another case study, it is shown how the HVDC link can help to share dynamic frequency reserves in order to not jeopardise the stability of the system. A last example investigates the effect of a DC fault on AC transient stability and how the control can help improving the system response.
\end{abstract}

\section{Introduction}

The structure and operation of electric transmission systems is evolving faster than ever. The introduction of renewable energies in centralised facilities often located far from end-users, as well as the disconnection of conventional generation units, pose new challenges for system operators. Because of these trends, the transport of bulk-power over long distances has become a challenging necessity. Indeed, if large amounts of power are transported over large $\mathrm{AC}$ corridors, the security of the system can be at risk [1]. A possible solution to assure the system security under these conditions is the reinforcement of the transmission system. To this end, the High Voltage Direct Current (HVDC) technology has raised not only as a cost-effective solution for long distance transmission but also presents other technical advantages over AC lines. When a system is reinforced with an HVDC line based on Voltage Source Converters (VSC-HVDC), the fast and independent control of active and reactive power gives the possibility to use the VSC-HVDC link to enhance the stability of the surrounding AC grid. In fact, dynamic stability studies have been performed over many decades showing that power modulation of HVDC links can enhance rotor angle stability. The injection of active and reactive power by HVDC systems allows to damp power oscillations as well as to counteract power imbalances, which can be the source of transient stability problems in a multi-machine system when a disturbance occurs. Actually, as defined in [2], it is already expected for the HVDC systems to participate on the stability enhancement of the surrounding system. This can be done by means of supplementary controllers such as the one proposed in this paper.

Power system transient stability stands for the ability of the system to keep synchronism after being subjected to a large disturbance such as a three-phase fault [3]. Its assessment requires the analysis of the systems described in their non-linear nature, which can be complex, especially when there is a large number of dynamic elements. The main tasks of the Transient Stability Assessment (TSA) consist in:
- Providing transient stability limits: approximations of the Region Of Attraction (ROA) of the power system, i.e. how far the system can move away from its equilibrium point without losing synchronism. - Providing transient stability margins: indicators of how close a system is to the transient stability limit following a given disturbance.

In power system engineering, the most common practice is to quantify these limits and margins in terms of the Critical Clearing Time (CCT) for a given disturbance. The CCT can be computed by iterative numerical solution of the systems' equations. Alternatively, the so-called Direct Methods, discussed in the classical literature of power systems [4-7], give the possibility to analytically approximate the region of attraction of a system. These methods are based on the use of the Transient Energy Functions (TEF), and they aim to provide information about the stability limits and margins in terms of energy. Although conservative, these methods can assess stability limits independently from the experienced disturbance and without solution of the equations (which is not the case for the CCT). Therefore, to have more general conclusions, Direct Methods are used in this paper to compare the stability margins of an AC transmission system against its equivalent AC/DC system. The comparison of transient stability margins is used to highlight the need of HVDC power modulation through supplementary controls in AC/DC grids.

The study of supplementary controllers allowing to modulate the control variables of HVDC links for AC stability enhancement started almost at the same time as the HVDC technology itself. A survey on controllers for the particular use of power oscillation damping can be found in [8]. Supplementary controllers of HVDC links found in literature mainly differ depending on:

- HVDC technology (LCC or VSC),

- measured feedback signals (phase, voltages, etc...),

- control objectives (damp oscillations, security improvement, voltage stabilisation, etc.. ), 
- control input (active or reactive power, DC voltage, AC or DC current, etc..),

- applied control technique,

- the use (or not) of Wide Area Measurement Systems (WAMS),

- coordination of the HVDC link with other FACTS devices,

- topology of the AC/DC grid (embedded HVDC links or links connecting two asynchronous areas)

For decades, the transient stability problem has been treated via the control of the excitation of generators using the Automatic Voltage Regulators (AVR) and Power System Stabilisers (PSS). For this reason, in early development of point to point HVDC links, a natural choice was to equip them with PSSs aiming the stability of the surrounding AC grid [9]. Another intuitive control scheme consisted in modulating the HVDC power proportionally to the speed deviation of a nearby machine [10]. This early development led to the implementation of controllers on existing projects based on measurements done near one HVDC station $[9,11]$.

The introduction of WAMS allowed the implementation of control schemes using feedback signals measured at different locations of the power grid. For example, in $[12,13]$ using Lyapunov's theory, it was proven that transient stability is enhanced by modulating active power proportionally to the difference of frequency measured at the PCC of both converters (also analysed in $[14,15]$ ). This control scheme was recently implemented in the western North American Power System on a real time simulation platform with actual measurements from PMUs [16]. This results have been upgraded and extrapolated for the proposition of supplementary controllers of Multi-Terminal DC grids in [17]. Regarding the use of voltage phase angles, two industrial applications have been reported to modulate the power as a proportional function of the angle difference between inverter and rectifier sides $[18,19]$. Although this kind of control has been tested on real applications, no dynamic analysis has been done. Also, regarding the use of angles as feedback signal, recently a PSSlike control using angle difference as feedback signal was proposed in [20] for designing an oscillation damping control.

The implementation of real WAMS in different power systems [21] also gave value to the research done regarding advanced controllers, with more feedback signals and more control inputs. For instance, as for the coordination of different HVDC links, a centralised scheme using a model predictive control was presented in [22]. There, it is proposed to use speed measurements of different machines. A compilation of other results on supplementary controllers of HVDC links using WAMS can be found in [23].

Recently, promising tracks using the inner loops of the converter for improving transient stability have been proposed. In [24], the authors show that controlling the inverter (rectifier) station in order to emulate the behaviour of a synchronous motor (generator) has a favourable impact on transient stability. Furthermore, in $[25,26]$ the authors design robust inner controllers of the converters taking into account the dynamics of the surrounding AC grid. Such control techniques can be achieved only based on local measurements.

In the cited works above, the advantage of synchronising power injections (proportional to phase angle deviations) is not highlighted. To the authors' best knowledge, it has not been shown how the synchronisation of different regions is possible through the control of HVDC links even when no AC links are connecting those grids. The present work brings answers to these points, and in addition, analyses two different events poorly reported in the literature. The first one is the uncoordinated poor fast frequency response, and the second is the study of the impact of DC faults on the overall system stability.

The present paper is organised as follows. In section 2, a modelling technique allowing to represent mixed AC/DC systems as a set of ordinary differential equations is presented. In section 3, a comparison between an $\mathrm{AC}$ system and an equivalent AC/DC system is performed using Direct Methods. This comparison shows that HVDC systems with constant power references do not intrinsically increase transient stability margins as an $\mathrm{AC}$ line does. Therefore, the need of a supplementary control loop for the HVDC link to enhance the AC stability is highlighted. In section 4 , feedback linearization technique is used to derive a control law, and its physical meaning is studied. The proposed control law is based on three actions: damping power injection, synchronising power injection and feed-forward actions. In section 5, EMT simulations using detailed models are performed. The advantages of the proposed control are emphasised, through the analysis of different contingencies, such as three phase-faults, uncoordinated fast frequency response and DC faults.

\section{$2 \quad A C / D C$ Power systems modelling for transient stability studies}

In this section, the Internal Node Model (INM) of a multimachine/multi-converter power system is described. The INM allows to represent the system by a set of ordinary differential equations through reduction of the admittance matrix of the system $[27,28]$. For the derivation of the model, consider power system composed of $n$ generators and $m$ HVDC stations interconnected via a transmission network described by the nodal admittance matrix $\mathbf{Y}$.

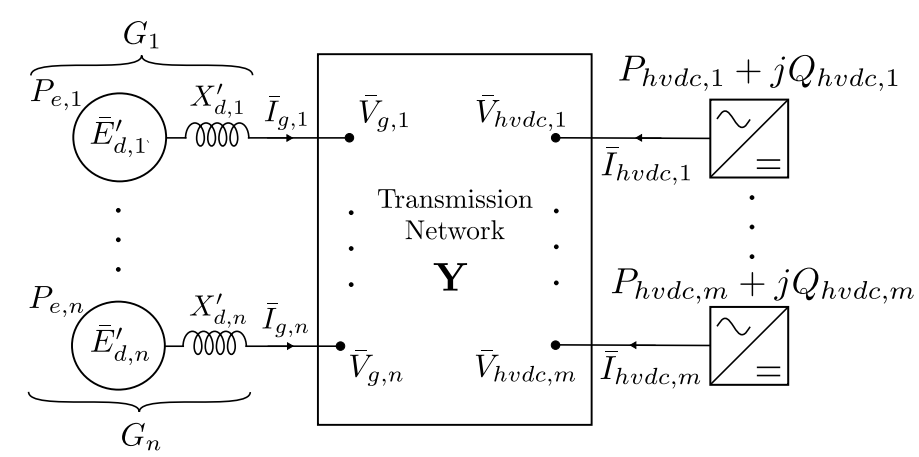

Fig. 1: Multi-machine/multi-converter power system

Synchronous generators are represented by the association of a complex voltage source representing the internal voltage of the generator $\bar{E}_{d, i}^{\prime}=E_{d, i}^{\prime} \angle \delta_{i}$ and the transient reactance $X_{d, i}^{\prime}$. The voltage $\bar{V}_{q, i}$ denotes the voltage at the terminals of the $i-t h$ generator and $V_{h v d c, k}=V_{h v d c, k} \angle \theta_{h v d c, k}$ is the voltage at the Point of Common Coupling (PCC) of the $k-t h$ converter. The equations of the multi-machine system are given by:

$$
\begin{aligned}
\dot{\delta}_{i} & =\omega_{i} \\
M_{i} \dot{\omega}_{i} & =-K_{D, i} \omega_{i}+P_{m, i}-P_{e, i}
\end{aligned}
$$

where for the $i-t h$ generator $(\forall i=1, \ldots, n), \delta_{i}$ represents the rotor angle deviation with respect to a synchronous reference, $\omega_{i}$ is the rotor speed deviation with respect to the synchronous speed $\omega_{s}, M_{i}$ is the inertia coefficient, $P_{m, i}$ is the mechanical input power, $P_{e, i}$ is the electrical output power. In the classical model, the angle of the internal voltage $E_{d, i}^{\prime} \angle \delta_{i}$ represents also the rotor angle deviation $\delta_{i}$ of a synchronous generator with one pair of poles.

Regarding the converters, their dynamics are much faster when compared with the electromechanical dynamics of the generators. For the dynamics of interest, converters can be considered as complex current sources $\left(\bar{I}_{h v d c, k}\right)$ with independent active power $\left(P_{h v d c, k}\right)$ and reactive power $\left(Q_{h v d c, k}\right)$ injections. This assumption is particularly valid when inner controllers designed for decoupling the AC side and the DC side are used [29-33]. The controlled active and reactive power injections can be divided in two components as follows:

$$
\begin{aligned}
P_{h v d c, k} & =P_{h v d c 0, k}+\Delta P_{h v d c, k} \\
Q_{h v d c, k} & =Q_{h v d c 0, k}+\Delta Q_{h v d c, k}
\end{aligned}
$$

where $P_{h v d c 0, k}$ and $Q_{h v d c 0, k}$ are the set-points determined by the operator of the system and $\Delta P_{h v d c, k}$ and $\Delta Q_{h v d c, k}$ are the supplementary control references of the converters. 
The impact of the active and reactive power injections on the generators' dynamics is given by the development of the electrical output power term $\left(P_{e i}\right)$ in Equation (1). Using Kirchoff's law, we have that the relation between currents and voltages through the admittance matrix including the transient reactances of the synchronous generators $\mathbf{Y}_{\text {bus }}$ is given by:

$$
\left[\begin{array}{c}
\mathbf{I}_{g} \\
\mathbf{I}_{h v d c}
\end{array}\right]=\overbrace{\left[\begin{array}{ll}
\mathbf{Y}_{A} & \mathbf{Y}_{B} \\
\mathbf{Y}_{C} & \mathbf{Y}_{D}
\end{array}\right]}^{\mathbf{Y}_{\text {bus }}}\left[\begin{array}{c}
\mathbf{E}^{\prime}{ }_{d} \\
\mathbf{V}_{h v d c}
\end{array}\right]
$$

where $\mathbf{Y}_{A}, \mathbf{Y}_{B}, \mathbf{Y}_{C}$ and $\mathbf{Y}_{D}$ are of dimensions $(n \times n),(n \times m)$, $(m \times n)$ and $(m \times m)$ respectively. $\mathbf{I}_{g}$ and $\mathbf{E}^{\prime}{ }_{d}$ respectively contain the injected currents and internal voltages of generators. $\mathbf{I}_{h v d c}$ and $\mathbf{V}_{h v d c}$ are the injected currents and voltages at AC bus-bars of the converters [10]. We can solve for the generator's currents as follows:

$$
\mathbf{I}_{g}=\mathbf{Y}_{S N} \mathbf{E}_{d}^{\prime}+\mathbf{K}_{h v d c} \mathbf{I}_{h v d c}
$$

with $\mathbf{Y}_{S N}=\left(\mathbf{Y}_{A}-\mathbf{Y}_{B} \mathbf{Y}_{D}^{-1} \mathbf{Y}_{C}\right)$ and $\mathbf{K}_{h v d c}=\mathbf{Y}_{B} \mathbf{Y}_{D}^{-1}$. Matrix $\mathbf{Y}_{S N}$ is the matrix relating all generators voltages and currents, $\mathbf{K}_{h v d c}$ describes the effect of HVDC injected currents on the generator. Elements of $\mathbf{Y}_{S N}$ and $\mathbf{K}_{h v d c}$ are:

$$
\bar{Y}_{S N_{i j}}=G_{i j}+j B_{i j} \quad \text { and } \quad \bar{K}_{h v d c, i k}=D_{i k}^{h v d c}+j F_{i k}^{h v d c}
$$

$G_{i j}$ and $B_{i j}$ are the equivalent conductance and susceptance between generators $i$ and $j . D_{i k}^{h v d c}$ and $F_{i k}^{h v d c}$ are the real and imaginary parts of the element $K_{h v d c, i k}$ which denote the effect of the injected current of the $k-t h$ converter on the $i-t h$ generator. Then, the expression of the active power supplied by the $i-t h$ machine $P_{e, i}$ in Equation (1), is developed as:

$$
P_{e i}=\Re\left[\bar{E}_{d i}^{\prime} \sum_{j=1}^{n} \bar{Y}_{S N_{i j}}^{*} \bar{E}_{d j}^{\prime *}-\bar{E}_{d i}^{\prime} \sum_{k=1}^{m} \bar{K}_{h v d c_{i k}}^{*} \bar{I}_{h v d c_{k}}^{*}\right]
$$

Substituting (5) into (6), the electric power supplied by the $i-t h$ generator is derived as:

$$
\begin{aligned}
& P_{e, i}=\sum_{j=1}^{n} E_{d, i}^{\prime} E_{d, j}^{\prime}\left(G_{i j} \cos \delta_{i j}+B_{i j} \sin \delta_{i j}\right) \\
& +\Re\left[\sum_{k=1}^{m} \frac{\bar{E}_{d, i}^{\prime}}{\bar{V}_{h v d c, k}}\left(D_{i k}^{h v d c}+j F_{i k}^{h v d c}\right)\left(P_{h v d c, k}+j Q_{h v d c, k}\right)\right]
\end{aligned}
$$

with $\delta_{i j}=\delta_{i}-\delta_{j}$. The complex ratio of voltages $\left(\bar{E}_{d i}^{\prime} / \bar{V}_{h v d c_{k}}\right)$ can be approximated to constant values [10]. Following this assumption, and applying Equations (2) into Equation (7), the electrical power can be expressed as follows:

$$
P_{e, i}=P_{g g, i}+\Delta P_{g v, i}
$$

with

$$
\begin{aligned}
P_{g g, i} & =\sum_{j=1}^{n} E_{d, i}^{\prime} E_{d, j}^{\prime}\left(G_{i j} \cos \delta_{i j}+B_{i j} \sin \delta_{i j}\right) \\
& +\sum_{k=1}^{m} a_{i k}^{h v d c} P_{h v d c 0, k}+\sum_{k=1}^{m} b_{i k}^{h v d c} Q_{h v d c 0, k} \\
\Delta P_{g v, i} & =\sum_{k=1}^{m} a_{i k}^{h v d c} \Delta P_{h v d c, k}+\sum_{k=1}^{m} b_{i k}^{h v d c} \Delta Q_{h v d c, k}
\end{aligned}
$$

where $a_{i k}^{h v d c}$ and $b_{i k}^{h v d c}$ are called "distribution factors" and they are computed as follows:

$$
\begin{aligned}
a_{i k}^{h v d c} & =\frac{E_{d, i}^{\prime}}{V_{h v d c, k}}\left[F_{i k}^{h v d c} \cos \left(\delta_{i}-\theta_{h v d c, k}\right)+D_{i k}^{h v d c} \sin \left(\delta_{i}-\theta_{h v d c, k}\right)\right] \\
b_{i k}^{h v d c} & =\frac{E_{d, i}^{\prime}}{V_{h v d c, k}}\left[D_{i k}^{h v d c} \cos \left(\delta_{i}-\theta_{h v d c, k}\right)-F_{i k}^{h v d c} \sin \left(\delta_{i}-\theta_{h v d c, k}\right)\right]
\end{aligned}
$$

The same procedure can be performed in order to include loads with constant power characteristic [4] as further done in this paper. Finally, Equations (1) and 9 can be rewritten to obtain the state space model of the AC power system with HVDC power injections used in this paper for the derivation of the control law, which is given by:

$$
\dot{\boldsymbol{x}}=\left[\begin{array}{c}
\dot{\boldsymbol{\delta}} \\
\dot{\boldsymbol{\omega}}
\end{array}\right]=f(\boldsymbol{\delta}, \boldsymbol{\omega})+\left[\begin{array}{ll}
\boldsymbol{B}_{\boldsymbol{P}} & \boldsymbol{B}_{\boldsymbol{Q}}
\end{array}\right] \boldsymbol{u}
$$

where

$$
\begin{aligned}
& \boldsymbol{\delta}=\left[\delta_{1} \ldots \delta_{n}\right]^{T} \quad, \quad \boldsymbol{\omega}=\left[\omega_{1} \ldots \omega_{n}\right]^{T} \\
& \boldsymbol{u}=\left[\Delta P_{h v d c, 1} \ldots \Delta P_{h v d c, k} \quad \Delta Q_{h v d c, 1} \ldots \Delta Q_{h v d c, k}\right]^{T} \\
& f(\boldsymbol{\delta}, \boldsymbol{\omega})=\left[\begin{array}{c}
\omega_{1} \\
\vdots \\
\omega_{n} \\
\frac{1}{M_{1}}\left(P_{m, 1}-K_{D, 1} \omega_{i}-P_{g g, 1}(\boldsymbol{\delta})\right) \\
\vdots \\
\frac{1}{M_{n}}\left(P_{m, n}-K_{D, n} \omega_{n}-P_{g g, n}(\boldsymbol{\delta})\right)
\end{array}\right]
\end{aligned}
$$

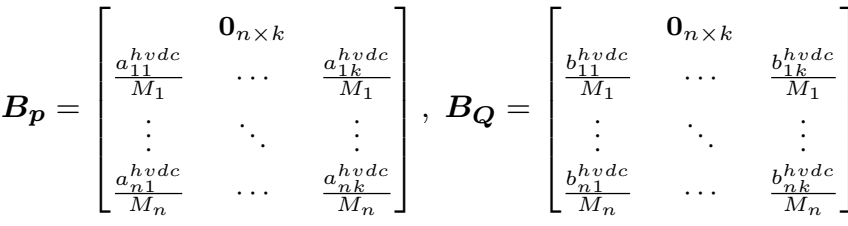

\section{Impact of embedded HVDC on AC grid stability}

In this section, Direct Methods are used to assess the transient stability of the Single Machine Infinite Bus (SMIB) system in Figure 2. The case corresponds to an $\mathrm{AC}$ system that has been reinforced by two different means: the system in figure $2 \mathrm{a}$ has been reinforced with an AC line, while in the case represented in Figure 2b, an HVDC link has been chosen for the reinforcement.

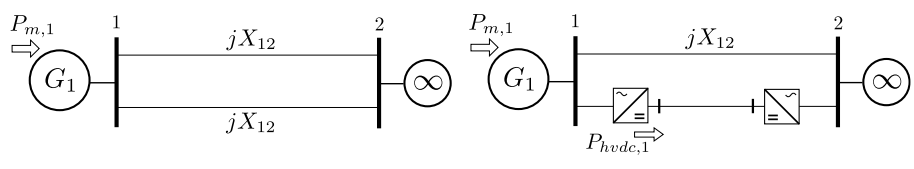

(a) AC SMIB

(b) AC/DC SMIB

Fig. 2: Comparison between: (a) AC SMIB and (b) AC/DC SMIB

All the AC lines are assumed to be loss-less lines of reactance $X_{12}$. The internal reactance of the generator is assumed negligible against the reactance of the $\mathrm{AC}$ transmission line (i.e. $X_{d 1}^{\prime}<<$ $X_{12}$ ). Using the methodology proposed in Section 2, the dynamics of both systems are described by:

- a) SMIB AC system:

$$
M_{1} \dot{\omega}_{1}+k_{D, 1} \omega_{1}=P_{m, 1}-\overbrace{\left(2 P_{\max } \sin \delta_{1}\right)}^{P_{e, 1}\left(\delta_{1}\right)}
$$


- b) SMIB AC/DC system:

$$
M_{1} \dot{\omega}_{1}+k_{D, 1} \omega_{1}=P_{m, 1}-\overbrace{\left(P_{\max } \sin \delta_{1}+P_{h v d c, 1}\right)}^{P_{e, 1}\left(\delta_{1}\right)}
$$

with $P_{\max }=E_{d, 1}^{\prime} V_{2} / X_{12}$.

\subsection{The Equal Area Criterion}

The power-angle (P- $\delta$ ) curve of both systems is depicted in Figure 3. This curve represents the power delivered by the generator as function of the rotor angle. By means of the Equal Area Criterion (EAC), the stability margins of both cases can be analysed [34].

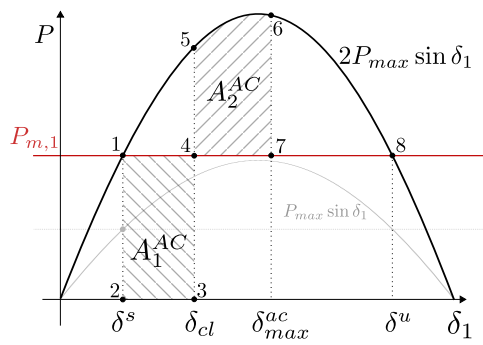

AC SMIB

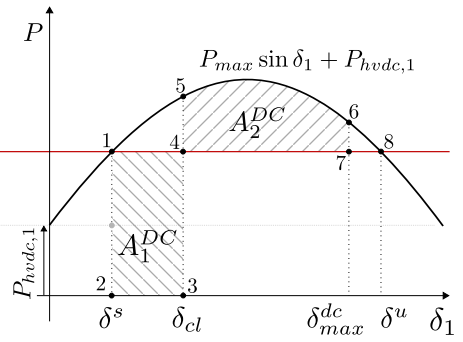

AC/DC SMIB
Fig. 3: Equal area criterion comparison

In this comparison, every transmission line (HVAC or HVDC) in both systems transmits the same amount of power in the pre-fault steady-state situation. Therefore, the constant active power reference for the HVDC link is set to be equal to the active power for one AC line in steady state (i.e. $P_{h v d c_{1}}=P_{\max } \sin \delta^{s}$ ). This assumption allows to have the same equilibrium points in both systems (the same angle in steady state). In the plotted region systems have two equilibrium points, one being stable and the other unstable [1]. It is possible to note that, the stable equilibrium point (SEP) of both systems is the same $\left(\delta_{1}=\delta^{s}\right)$, as well as their unstable equilibrium point (UEP) $\left(\delta_{1}=\delta^{u}\right)$.

Let us assume that a temporary three-phase fault occurs in bus 1 . When the fault occurs, the power delivered by the generator suddenly changes from point 1 to 2 in Figure 3 (it goes to zero). During the fault, both systems accelerate following the same trajectory as the machine's delivered power is zero until the fault disappears. Due to this acceleration, the angle increases from $\delta_{s}$ to $\delta_{c l}$. During the timespan between fault occurrence and fault disappearance, the system acquires a kinetic energy proportional to surface 1-2-3-4. For the described fault, the acquired energy of both systems is the same (i.e. $A_{1}^{A C}=A_{1}^{D C}$ ).

When the fault is cleared, the systems get back to their pre-fault power-angle curve (trajectories go from points 3 to 5 in Figure 3). The angle continues to deviate until the kinetic energy absorbed during the fault is expended by transferring it to the grid [1]. The systems move from 5 to 6 , such that area $A_{2}^{A C}\left(A_{2}^{D C}\right)$ is equal to area $A_{1}^{A C}\left(A_{1}^{D C}\right)$. For the studied fault, it can be observed that the maximum angle reached during the first swing in the AC/DC SMIB is larger than the one in the AC SMIB (i.e. $\delta_{\max }^{D C}<\delta_{\max }^{A C}$ ). This shows that the AC/DC SMIB is closer to instability for the same fault. Furthermore, after fault clearing, the available energy for decelerating the system is proportional to the surface 4-5-8, it can be easily observed that in the AC/DC SMIB, this surface is smaller than the surface in the AC SMIB case. This means that transient stability margins are larger in the AC SMIB than in the AC/DC SMIB. This phenomenon is due to the nature of the AC lines, their synchronizing power injections (AC lines transmit power as function of the transport angle) contribute to decrease the separation of areas. In the AC/DC SMIB case, as the HVDC link is set in constant power mode, its contribution against angle deviations is nonexistent.

\subsection{Comparison via Energy functions}

For more general conclusions, the transient stability of both systems can be compared by means of the Transient Energy Functions (TEF). These functions represent the sum of the kinetic and potential energy of the system [35]. For a SMIB system represented by Equation (11), the TEF can be found by computing the first integral of motion, as follows:

$$
W\left(\omega_{1}, \delta_{1}\right)=\overbrace{\frac{1}{2} M_{1} \omega_{1}^{2}}^{W_{K E}}+\overbrace{\int_{\delta_{1}}-\left[P_{m, 1}-P_{e, 1}\left(\delta_{1}\right)\right] d \delta_{1}}^{W_{P E}}
$$

where the total energy $W$ is the sum of the kinetic and potential energy noted $W_{K E}$ and $W_{P E}$ respectively. From Equation (14), it must be noted that there is a relation between the Equal Area Criterion and the potential energy function $W_{P E}$. Indeed, $W_{P E}$ represents the surface 1-6-7 on the equal area criterion in Figure 3.

The transient energy functions of the described systems under comparison are the following:

- a) AC SMIB system:

$$
\begin{aligned}
& W^{a c}=\frac{1}{2} M_{1} \omega_{1}^{2} \\
& -\overbrace{P_{m, 1}\left(\delta_{1}-\delta^{s}\right)-2 P_{\max }\left(\cos \delta_{1}-\cos \delta^{s}\right)}^{W_{P E}^{a c}\left(\delta_{1}\right)}
\end{aligned}
$$

- b) AC/DC SMIB system:

$$
\begin{aligned}
& W^{d c}=\frac{1}{2} M_{1} \omega_{1}^{2} \\
& -\overbrace{\left(P_{m, 1}-P_{h v d c, 1}\right)\left(\delta_{1}-\delta^{s}\right)-P_{\max }\left(\cos \delta_{1}-\cos \delta^{s}\right)}^{W_{P E}^{d c}\left(\delta_{1}\right)}
\end{aligned}
$$

where $W_{P E}^{a c}$ and $W_{P E}^{d c}$ stand for the potential energy of the AC SMIB and the AC/DC SMIB respectively. The evaluation of the time derivative of the total energy ( $W^{a c}$ and $W^{d c}$ ) gives an estimation on how the total energy decays when the system is subjected to a disturbance. The computation of the time derivative of Equations (15) and (16) yields (see [12] for more details):

$$
\dot{W}^{a c}=\dot{W}^{d c}=-k_{D, 1} \omega_{1}^{2}
$$

This equation shows that the energy decays at a rate proportional to the damping coefficient $\left(k_{D, 1}>0\right)$ and the square of the speed deviation. It is also found that the rate of change of energy in both systems is the same. Therefore, for a more convenient comparison it is proposed to analyse the potential energy on both systems. For this purpose, the potential energy functions $W_{P E}^{a c}$ and $W_{P E}^{d c}$ are plotted alongside the power-angle curve of each system in Figure 4.

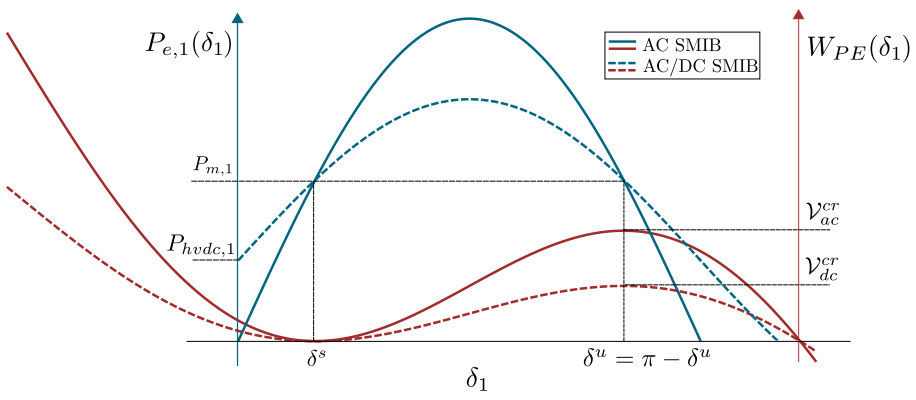

Fig. 4: Potential energy and power-angle curve comparison.

The evolution of the potential energy as function of the angle deviation shows that there is a local minimum in the SEP. Besides, 
as described in [6], the Potential Energy Boundary Method states that there is a local maximum in the UEP $\left(\delta_{1}=\delta^{u}, \omega_{1}=0\right)$ as it is confirmed in Figure 4. According to the the Closest Unstable Equilibrium Point method in [35], an approximation of the stability boundary can be made by finding the equi-potential contour crossing the closest UEP. The potential energy value at this point is defined as the critical energy $\mathcal{V}^{c r}$. In both systems under study, $\mathcal{V}^{c r}$ is equal to the potential energy at the UEP. The comparison of the local maximum values of potential energy of both systems shows that the critical energy is bigger in the AC SMIB than in the AC/DC SMIB $\left(\mathcal{V}_{a c}^{c r}>\mathcal{V}_{d c}^{c r}\right)$. This means that for the systems under study the transient stability margins are bigger in the AC SMIB case.

The same comparison can be done for all stable equilibrium points. In order to do so, the critical energy $\mathcal{V}^{c r}$ as function of a given equilibrium point $\left(\delta_{1}=\delta^{s}, \omega_{1}=0\right)$ is expressed as follows:

- a) Critical energy for the AC SMIB system:

$$
\mathcal{V}_{a c}^{c r}\left(\delta^{s}\right)=W^{a c}\left(\pi-\delta^{s}, 0\right)=P_{m, 1}\left(2 \delta^{s}-\pi\right)+4 P_{\max } \cos \delta^{s}
$$

- b) Critical energy for the AC/DC SMIB (the power reference of the HVDC is constant and it is equal to $P_{h v d c, 1}=P_{\max } \sin \delta^{s}$ ):

$$
\begin{aligned}
\mathcal{V}_{d c}^{c r}\left(\delta^{s}\right)= & W^{d c}\left(\pi-\delta^{s}, 0\right)=\left(P_{m, 1}-P_{\max } \sin \delta^{s}\right)\left(2 \delta^{s}-\pi\right) \\
& +2 P_{\max } \cos \delta^{s}
\end{aligned}
$$

Dividing Equations (18) and 19 by $P_{\max }$ and eliminating the common terms, it can be shown that $\mathcal{V}_{a c}^{c r}>\mathcal{V}_{d c}^{c r}$ when

$$
2 \cos \delta^{s}>\sin \delta^{s} \cdot\left(\pi-2 \delta^{s}\right)
$$

which is true for all stable equilibrium points of interest (i.e. $0<$ $\left.\delta^{s}<\pi / 2\right)$. Consequently it can be stated that, in all the stable equilibrium points $\left(0<\delta^{s}<\pi / 2\right)$, the critical energy of the AC SMIB system is higher than the critical energy of the AC/DC SMIB. Further analysis can show that, for a given equilibrium point $\left(0, \delta^{s}\right)$, all positive values of $P_{h v d c_{1}}$ will result in lower values of critical energy than its equivalent AC SMIB system.

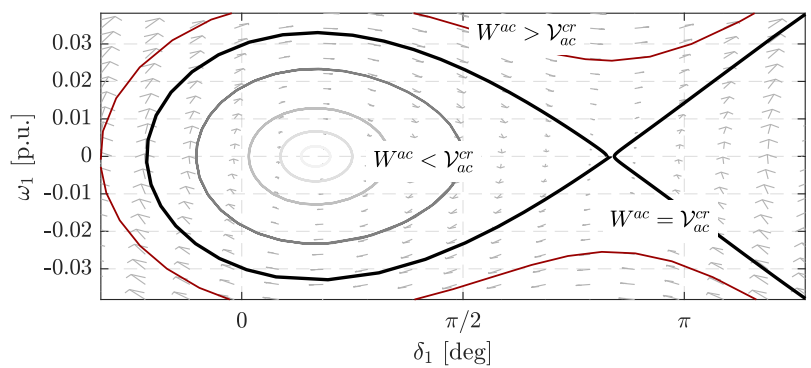

(a) AC SMIB

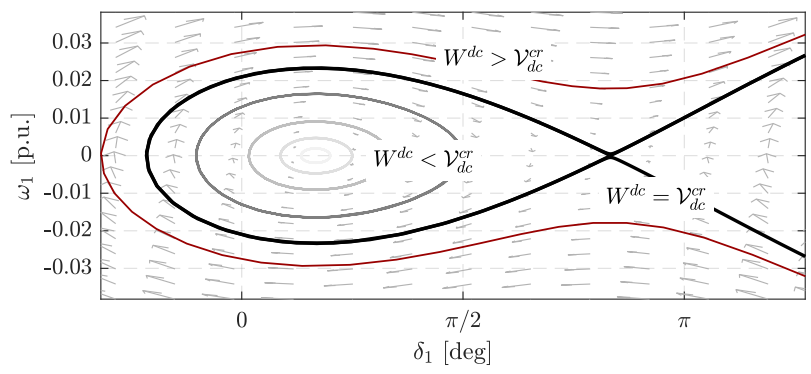

(b) AC/DC SMIB

Fig. 5: Comparison of the regions of attraction. Characteristics of the system: $\delta^{s}=30, P_{m, 1}=1 \mathrm{pu}, P_{\max }=1 \mathrm{pu}, P_{h v d c, 1}=$ $0.5 \mathrm{pu}, k_{D, 1}=0, M=0.12 \mathrm{MW} \mathrm{s} \mathrm{s}^{2} / \mathrm{MVA} \operatorname{rad}\left(\right.$ i.e. $H_{1}=4 \mathrm{~s}$ ).
The vector field and the region of attraction of both systems are obtained by numerical integration and are depicted in the phase plane in Figure 5. The SEP is $\left(\delta_{1}=\delta^{s}=30^{\circ}, \omega_{1}=0\right)$, and the region of attraction is delimited by the thick line. Some trajectories starting at different initial points (or points just after fault clearing) are also depicted. It can be observed that, when the post-fault trajectory starts inside the region of attraction, its energy is lower than the critical energy $\left(W<\mathcal{V}^{c r}\right)$ and the system remains stable, otherwise the system will diverge. It can be also seen that, as damping has been neglected $\left(K_{D, 1}\right)$, those trajectories continue to oscillate. As suggested by Equation (17) if the damping is neglected, the total energy $\left(W^{a c}\right.$ and $W^{d c}$ ) is constant after fault clearing (equiscalar contour). On the contrary, if the damping coefficient is positive, the energy dissipation will be positive leading the system to reach back the SEP.

\subsection{Eigenvalue analysis}

If after the first swing, the described SMIB system remain stable, and the damping coefficient is positive, the systems undergo oscillations until they reach their equilibrium point. These oscillations in power systems are generally analysed using the Lyapunov's first method. Linearization of the system around its equilibrium point can supply information about the frequency and damping factor of such oscillations. Linearizing Equations (12) and (13) around an stable equilibrium point, the eigenvalues of the SMIB system can be found. The damping factor $\xi$ and the oscillation frequency $f$ are found to be:

$$
\xi=\frac{K_{D, 1}}{2 \sqrt{K_{s} M_{1}}}, \quad f=\sqrt{\frac{K_{s}}{M_{1}}-\left(\frac{K_{D, 1}}{2 M_{1}}\right)^{2}}
$$

where $K_{s}$ is known in the literature as the synchronising power constant and, in this case, represents the slope of the power-angle curve. For both systems it can be calculated as follows:

- a) SMIB AC system

$$
K_{s}=K_{s}^{A C}=2 P_{\max } \cos \delta^{s}
$$

- b) SMIB AC/DC system (the power reference of the HVDC is constant and equal to $P_{h v d c, 1}=P_{\max } \sin \delta^{s}$ )

$$
K_{s}=K_{s}^{D C}=P_{\max } \cos \delta^{s}
$$

The synchronising power constant from case (a) $K_{s}^{A C}$ is bigger than the one in case (b) $K_{s}^{D C}$ for all the stable values of $\delta^{s}$. Consequently, the damping coefficient is higher for the hybrid AC/DC case than in the pure $\mathrm{AC}$ system.

It is possible to conclude, that HVDC links with constant references can damp power oscillations in a mixed AC/DC system, with respect to their equivalent $\mathrm{AC}$ system; as it has been actually observed by power system operators (e.g. [36]). However it doesn't mean that transient stability is enhanced, as it was previously shown in this Section.

\section{$4 \quad$ Linearizing feedback control}

In order to enhance the stability margins of the $\mathrm{AC}$ network, the active power references of the VSC-HVDC are modulated based on feedback linearization techniques, such as to actively support the $\mathrm{AC}$ grid. The idea behind the feedback linearisation technique is to compensate the nonlinearities of the system by a control signal, produced by feedback of measured variables and knowledge of the system [37]. The obtained system, with reduced nonlinearities is further controlled applying linear control techniques for deciding the dynamic behaviour of the system. The proposed control is used to derive a supplementary control scheme which computes the necessary active power modulation for the power-mode converter allowing to improve the rotor angle stability of the surrounding $\mathrm{AC}$ grid, damp the electro-mechanical oscillations and to ensure the synchronisation of two AC interconnected networks. 


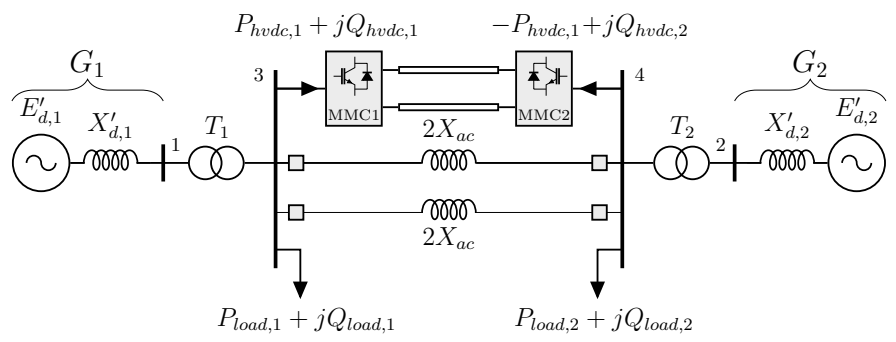

Fig. 6: 2-Area 2-Machines AC/DC power system

Following the procedure described in Section 2, and neglecting damping effects, the dynamic equations of the power system depicted in Figure 6 are given by:

$$
\left[\begin{array}{c}
{\left[\begin{array}{c}
\dot{\omega}_{1} \\
\dot{\omega}_{2} \\
\dot{\delta}_{1} \\
\dot{\delta}_{2}
\end{array}\right]=\left[\begin{array}{c}
\frac{1}{M_{1}}\left(P_{m 1}-\frac{E^{\prime}{ }_{d 1} E^{\prime} d 2}{X_{e q}} \sin \left(\delta_{1}-\delta_{2}\right)\right. \\
\left.-a_{11}^{L} P_{L 1}-a_{12}^{L} P_{L 2}-\left(a_{11}^{h v d c}+a_{12}^{h v d c}\right) P_{h v d c 0,1}\right) \\
\frac{1}{M_{2}}\left(P_{m 2}-\frac{E^{\prime}{ }_{d 1} E^{\prime} d 2}{X_{e q}} \sin \left(\delta_{2}-\delta_{1}\right)\right. \\
\left.-a_{21}^{L} P_{L 1}-a_{22}^{L} P_{L 2}+\left(a_{21}^{h v d c}+a_{22}^{h v d c}\right) P_{h v d c 0,1}\right) \\
\omega_{1} \\
\omega_{2}
\end{array}\right]} \\
+\left[\begin{array}{c}
\frac{1}{M_{1}}\left(a_{11}^{h v d c}+a_{12}^{h v d c}\right) \\
-\frac{1}{M_{2}}\left(a_{21}^{h v d c}+a_{22}^{h v d c}\right) \\
0 \\
0
\end{array}\right] \Delta P_{h v d c_{1}}
\end{array}\right.
$$

where $\Delta P_{h v d c_{1}}$ stands for the control input and it represents the supplementary power injection of the VSC-HVDC link and coefficients $a_{i l}^{L}$ are the distribution factors expressing the impact of the $l-t h$ load on the $i-t h$ generator. The equivalent reactance is the sum of the reactances between generator G1 and G2 (i.e. $X_{e q}=X_{d 1}^{\prime}+X_{T 1}+X_{a c}+X_{T 2}+X_{d 2}^{\prime}$ ). Generators are said to be in synchronous equilibrium if all angular distances $\delta_{i}-\delta_{j}$ are bounded and all frequencies are identical $\omega_{i}=\omega_{j}$, therefore the objective of the control is to make $\omega_{1}-\omega_{2}=0$. The error between the two regions can be modelled following the change of variables $\omega_{1}-\omega_{2}=\omega_{12}$ and $\delta_{1}-\delta_{2}=\delta_{12}$ as:

$$
\begin{aligned}
\ddot{\delta}_{12} & =-\frac{M_{1}+M_{2}}{M_{1} M_{2}} \frac{E^{\prime}{ }_{d 1} E^{\prime} d 2}{X_{e q}} \sin \left(\delta_{12}\right) \\
& +\frac{1}{M_{1}} P_{m 1}-\frac{1}{M_{2}} P_{m 2} \\
& -\left(\frac{a_{11}^{L}}{M_{1}}-\frac{a_{21}^{L}}{M_{2}}\right) P_{L 1}+\left(\frac{a_{12}^{L}}{M_{1}}-\frac{a_{22}^{L}}{M_{2}}\right) P_{L 2} \\
& +\left(\frac{a_{1}^{h v d c}}{M_{1}}+\frac{a_{2}^{h v d c}}{M_{2}}\right) P_{h v d c 0,1} \\
& +\left(\frac{a_{1}^{h v d c}}{M_{1}}+\frac{a_{2}^{h v d c}}{M_{2}}\right) \Delta P_{h v d c 0,1}
\end{aligned}
$$

with $\dot{\delta}_{12}=\omega_{12}$. It can be observed that using Equation (25), the system is now written in strict-feedback form (see [38]), where:

$$
\ddot{\delta}_{12}=f\left(\delta_{12}\right)+c+b u
$$

with $u$ the control input, $f\left(\delta_{12}\right)$ is the nonlinear function of the angle difference, and $c$ is a constant making its derivative equal to zero in steady state (i.e. $\ddot{\delta}_{12}=\dot{\delta}_{12}=0$ ). The linearizing feedback control law can be computed as follows:

$$
u=u_{l f}+v=-b^{-1}\left(f\left(\delta_{12}\right)+c+v\right)
$$

where $u_{l f}$ is the linearizing feedback part of the control law and $v$ introduces the linear dynamics that are to be imposed to the system. For the system represented in Equation (25) the linearizing control law is given by:

$$
\begin{aligned}
u= & -P_{h v d c 0,1}-\frac{M_{1} M_{2}}{a_{1}^{h v d c} M_{1}+a_{2}^{h v d c} M_{2}}\left[\frac{M_{1}+M_{2}}{M_{1} M_{2}} \frac{E_{d 1}^{\prime} E_{d 2}^{\prime}}{X_{e q}} \sin \delta_{12}\right) \\
& \left.+\frac{P_{m 1}}{M_{1}}-\frac{P_{m 2}}{M_{2}}-\left(\frac{a_{11}^{L}}{M_{1}}-\frac{a_{21}^{L}}{M_{2}}\right) P_{L 1}+\left(\frac{a_{12}^{L}}{M_{1}}-\frac{a_{22}^{L}}{M_{2}}\right) P_{L 2}-v\right]
\end{aligned}
$$

Note that if the internal reactance of the machines and the transformer are small compared to the AC line $\left(X_{d 1}^{\prime}<<X_{a c}\right)$, then $a_{21}^{L}=a_{12}^{L}=0$ and $a_{2}^{h v d c}=a_{2}^{h v d c}=1$, and the system is found to be described by:

$$
\begin{gathered}
\ddot{\delta}_{12}=\frac{P_{m 1}-P_{L 1}}{M_{1}}-\frac{P_{m 2}-P_{L 1}}{M_{2}} \\
-\frac{M_{1}+M_{2}}{M_{1} M_{2}}\left(P_{h v d c 0,1}+\frac{E^{\prime}{ }_{d 1} E^{\prime}{ }_{d 2}}{X_{a c}} \sin \left(\delta_{12}\right)+\Delta P_{h v d c_{1}}\right)
\end{gathered}
$$

Then the linearizing control law is:

$$
\begin{gathered}
u=-P_{h v d c 0,1}-\frac{E_{d 1}^{\prime} E_{d 2}^{\prime}}{X_{e q}} \sin \left(\delta_{12}\right) \\
+\frac{M_{1} M_{2}}{M_{1}+M_{2}}\left(\frac{P_{m 1}-P_{L 1}}{M_{1}}-\frac{P_{m 2}-P_{L 1}}{M_{2}}\right)-\frac{M_{1} M_{2}}{M_{1}+M_{2}} v
\end{gathered}
$$

The first part of the control law compensates the nonlinearities of the original system, while the term $v$ is used to define the desired closed loop dynamics. Then using linear control techniques, $v$ can be designed to impose the electromechanical mode between two regions [39]:

$$
v=\left[\begin{array}{ll}
-K_{\delta} & -K_{\omega}
\end{array}\right]\left[\begin{array}{c}
\bar{\delta}_{12}-\delta_{12} \\
\omega_{12}
\end{array}\right]
$$

where $K_{\delta}$ and $K_{\omega}$ are control gains. Injecting the linear control law (31) and the feedback linearizing control law (28) into the system (25), the dynamics of the closed-loop are found to be:

$$
\ddot{\delta}_{12}=-K_{\omega} \dot{\delta}_{12}-K_{\delta}\left(\bar{\delta}_{12}-\delta_{12}\right)
$$

with $\dot{\delta}_{12}=\omega_{12}$. The control gains can be designed using the pole placement technique. For this case, the gains can be chosen as function of the desired natural frequency $\left(\omega_{n}\right)$ and damping coefficient $(\xi)$ of the controlled system, as follows:

$$
K_{\delta}=\omega_{n}^{2} \quad \text { and } \quad K_{\omega}=2 \xi \omega_{n}
$$

Since the system has been linearized by the control action, it can be concluded that the region of attraction of the controlled system is theoretically determined only by the power limits (rated power) of the VSC-HVDC link.

\subsection{Physical interpretation of the control actions}

The control law in (30) is composed of three main actions:

- The first action (noted $u_{l f}$ in Equation (27)) allows to compensate for nonlinearities of the system. This action can also work as a feedforward action that compensates disturbances, especially if some of those values are measured (e.g. the power flowing through the parallel AC transmission line). Indeed, from the control law (27) it can be remarked that the term $f\left(\delta_{12}\right)$ corresponds to the actual power flowing through the $\mathrm{AC}$ corridor, therefore the term $c$ corresponds to the scheduled power to flow through such AC corridor. This property can highly simplify the practical implementation of this control action.

- An action injecting power proportionally to the speed deviation of both regions (see Equation (31)), contributing to the damping torque of the system.

- An action injecting power proportionally to the transport angle between both regions (see Equation (31)), contributing to the synchronising torque. As it will be shown in the examples, this action allows to synchronise both regions even if the parallel AC lines are tripped. 


\section{Test of the proposed control under different disturbances}

In this section, the proposed control scheme is applied to two different systems using the electromagnetic transient software EMTP-RV. The interest of using an EMT software is to take into account the dynamics of the Phasor Measurement Units (PMU), detailed controls of the converters, as well as studying the behaviour of the control in case of a DC fault. The HVDC stations in the link are two 500MVA Half-bridge Modular Multilevel Converters linked by a $200 \mathrm{~km}$ wide-band DC cable model, the implemented EMT models are described in [40, 41].

In the first two examples of this section, the simulated power system corresponds to a two-area power system connected by two $200 \mathrm{~km}$ AC lines in parallel with a VSC-HVDC link as shown in Figure 6. In the simulated system, two 900MVA generators equipped with AVR and PSS are implemented. Their parameters are the ones described in [1]. The load in the first area is 300MW, while in the second area the load is $800 \mathrm{MW}$, so the power flowing through the $\mathrm{AC} / \mathrm{DC}$ corridor is $500 \mathrm{MW}$. The implemented supplementary control is depicted in Figure 7. By means of the PMUs, phase angle $\left(\delta_{i}\right)$ and electrical pulsation $\left(\omega_{i}\right)$ at the PCC of both converters are measured. The communication system between the PMUs and the controller is represented by a delay. In this article it was considered a delay of $60 \mathrm{~ms}$ [42]. The reference angle between both stations $\bar{\delta}_{12}$ and the scheduled power exchanged are signals received from a higher level controller.

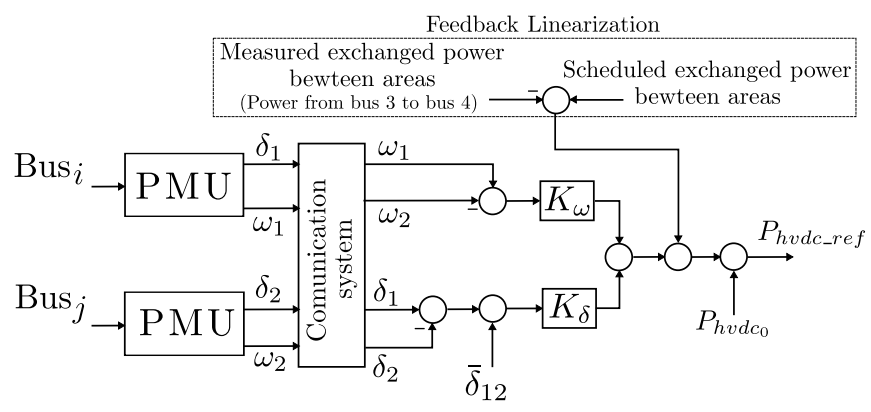

Fig. 7: Control implementation

\subsection{3-phase fault and trip of the faulted line}

The first case study corresponds to a $250 \mathrm{~ms} 3$-phase fault occurring in the middle of the AC line at $t=1 \mathrm{~s}$. Three different control strategies are compared:

- CR (Constant references): The power reference of the converter is maintained constant.

- POD (Power oscillation damping): The control proposed in [13] is implemented. This controller modulates the power reference as a function of the frequency deviation in both PCCs of the HVDC link $\left(\Delta P_{h v d c}=K\left(\omega_{1}-\omega_{2}\right)\right)$.

- NLF (Nonlinear Feedback): The proposed control is implemented and tuned to obtain an inter-area oscillation with a natural frequency of $\omega_{n}=0.5 \mathrm{~Hz}$ and a damping factor of $\xi=0.5$. The gains are $K_{\delta}$ $=1.7 \mathrm{MW} / \mathrm{deg}$ and $K_{\omega}=197 \mathrm{MW} / \mathrm{Hz}$

In Figure 8, it is seen that in the CR case, angle deviations during the first swing are higher compared with the other strategies. This means that the AC system is closer to lose transient stability (or power system split). With the CR strategy, it is also clearly observed that inter-area oscillations are poorly damped. When the POD strategy is implemented, it can be seen that the VSC-HVDC link is able to damp power oscillations via the modulation of the active power. It is also observed that the angle deviation during the first swing has been decreased. In the post-fault equilibrium point, the power reference of the HVDC goes back to its initial reference. In other words,

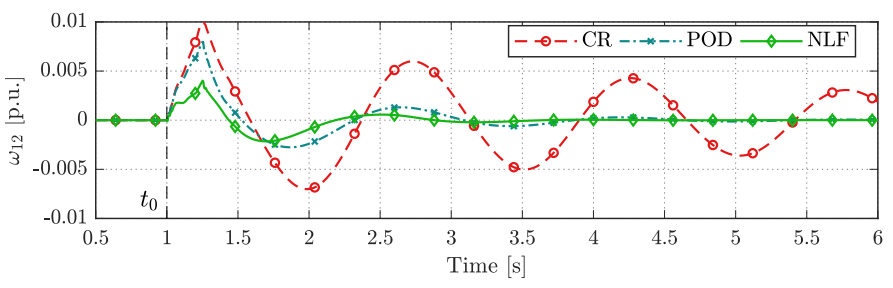

(a) Frequency difference between both areas

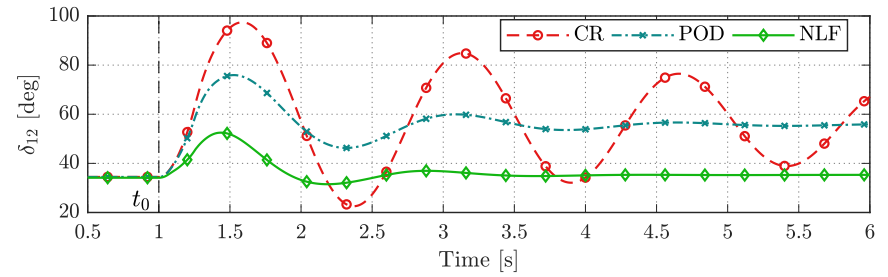

(b) Transport angle between both areas

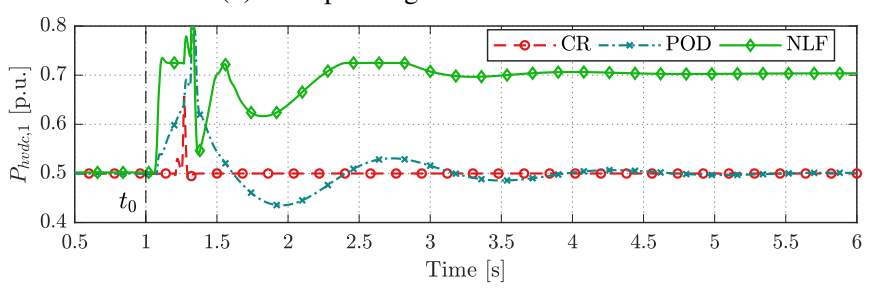

(c) Power transferred through the HVDC link

Fig. 8: Comparison of different control schemes after a 250ms threephase fault on one $\mathrm{AC}$ line followed by the line tripping

the power flowing through the tripped $\mathrm{AC}$ line before the fault, is reallocated on the remaining $\mathrm{AC}$ line. This is reflected in the increment of the angle in the post-fault steady-state compared with the pre-fault value $\left(35^{\circ}\right.$ before the fault against $58^{\circ}$ after the fault). The NFL control, by taking into account the disturbance in the system, will rapidly compensate the power imbalance due to the fault. This rapid action will limit the angle deviation between regions during the first swing. After the fault, if power is available, the power of the tripped AC line is reallocated to the HVDC link. This action will take the transport angle near its initial condition. As a consequence, stability margins of the post-fault configuration are similar as in the initial configuration.

In order to quantify the transient stability margins for each strategy, the Critical Clearing Time for two different fault locations are computed by iterative simulations and are summarised in Table 1 . In every case, the fault is cleared by the tripping of the faulty line. It can be observed that both supplementary controllers (POD and NLF) increase the stability limits with respect to the CR strategy. Besides, it is also shown that the stability margins are higher when the NLF strategy is implemented.

Table 1 Critical clearing times for different fault locations

\begin{tabular}{cccc}
\hline \multirow{2}{*}{ Case } & \multicolumn{3}{c}{ CCT(ms) } \\
\cline { 2 - 4 } & CR & POD & NLF \\
\hline Fault in the Middle of the line 3-4 & 290 & 355 & 460 \\
Fault near bus 3 & 120 & 220 & 335 \\
\hline
\end{tabular}

\subsection{Synchronisation in case of the disconnection of the AC parallel lines}

In this scenario, the disconnection of the whole group of AC transmission lines connecting both areas after a fault is studied. Let us consider that after a fault on the AC transmission lines, both of them are tripped, then no AC lines are interconnecting both areas. In order 
to preserve the power exchanged between areas, a standard solution is to reallocate the power transmitted by the AC lines into the VSCHVDC link (similar to the fast ramp strategy studied in [43]). Power reallocation would assure the right power exchange between both regions, however the split of the system won't be avoided. If both regions are not completely synchronised, the reconnection of the AC line cannot be done.

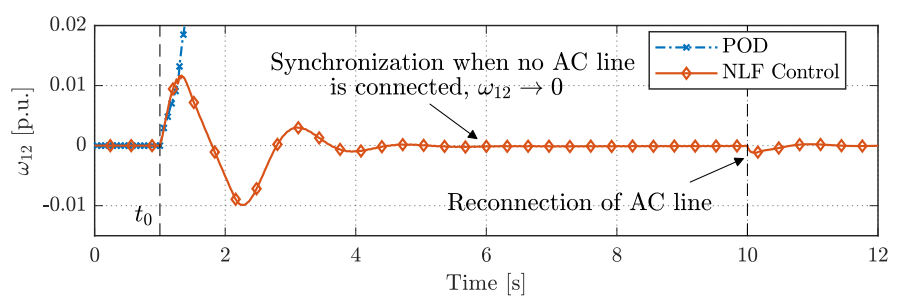

(a) Speed deviation of both areas

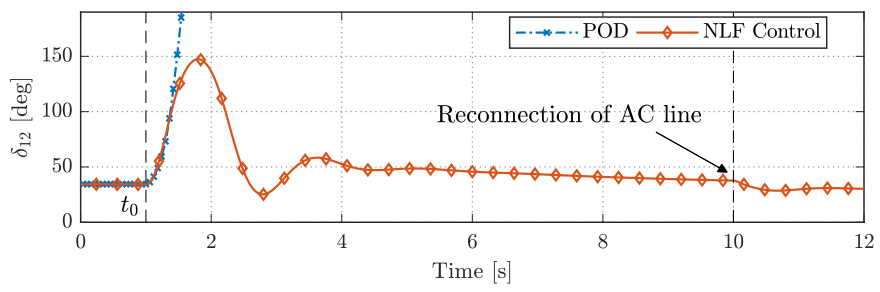

(b) Transport angle between both areas

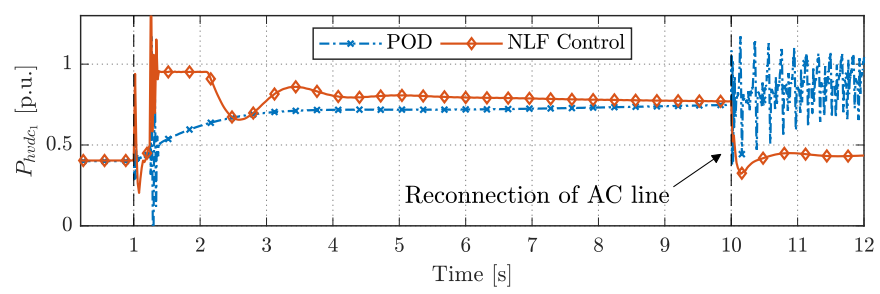

(c) Power transferred through the HVDC link

Fig. 9: Comparison of different control schemes when the $\mathrm{AC}$ transmission line is disconnected.

In this case study, two strategies are compared: POD and NFL. Figure 9 shows that, after a few seconds, the POD control is able to ensure the right power exchange between regions and takes the value of the speed difference $\omega_{12}$ to a stable value different from zero. This means that synchronism of both areas is not achieved. If the system are not synchronised it is not possible to reconnect the AC lines (a reconnection attempt is shown at $\mathrm{t}=10 \mathrm{~s}$ ).

The implementation of the NFL control shows that synchronisation of both areas can be achieved even if no physical AC line is connected. The proposed control scheme allows to automatically replace the disconnected group of lines while damping power oscillations, assuring power exchange and maintaining synchronism by emulating the behaviour of a modifiable transmission line connecting both areas. Besides, it can be seen that if the AC group of lines is reconnected later, at $\mathrm{t}=10 \mathrm{~s}$, the system remains stable and goes back to its initial equilibrium point. Synchronisation is achieved when $\omega_{12}=0$. If both areas are synchronised, the AC transmission line can be reconnected, even if the frequency of each region is not stabilised at $1 \mathrm{pu}$.

\subsection{Split of the system due to uncoordinated Frequency Response}

The system used in the last two cases correspond to a modified version of the Klein-Rogers-Kundur's two-area power system [1]. In this modified version the two areas are interconnected by a group of AC transmission lines and a VSC-HVDC link in bipolar configuration. In addition, power electronics interfaced power sources are connected in the first region in order to provide fast frequency response (FFR).

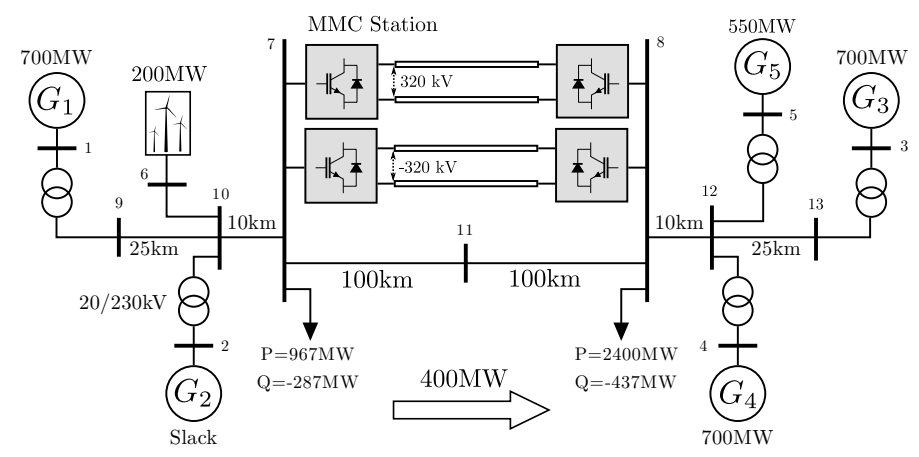

Fig. 10: Modified version of the Klein-Rogers-Kundur's two-area power system with power electronics interfaced energy sources

The procedure described in Section 4 is applied to this power system, and it is chosen to derive a control law that linearizes the input with respect to the error of frequency and angle between two regions given by:

$$
x=\left[\begin{array}{c}
\delta_{C O I_{1}}-\delta_{C O I_{2}} \\
\omega_{C O I_{1}}-\omega_{C O I_{2}}
\end{array}\right]
$$

where $\delta_{\mathrm{COI}_{1}}$ and $\delta_{\mathrm{COI}_{2}}$ are the angles of the centre of inertia (COI) of Area 1 and Area 2 respectively, $\omega_{\mathrm{COI}_{1}}$ and $\omega_{\mathrm{COI}_{2}}$ are the frequencies of the COI of Areas 1 and 2.

$$
\begin{gathered}
\delta_{C O I_{q}}=\frac{1}{M_{T}} \sum_{i=1}^{p} M_{i} \delta_{i}, \quad \omega_{C O I_{q}}=\frac{1}{M_{T}} \sum_{i=1}^{p} M_{i} \omega_{i} \\
M_{T}=\sum_{i=1}^{p} M_{i}
\end{gathered}
$$

where $p$ is the number of generators of synchronous generators in the Area $q$ of interest.

5.3.1 Poorly coordinated frequency response: A result of the increase in the penetration of renewable energies in a grid is the loss of inertia. The lack of inertia in the grid will lead to a more volatile power system. Controllable devices such as HVDC transmission and Power electronics interface sources must take part in the stabilisation of the grid. As reported in [44], one possibility to do so, is to make the renewable sources participate into frequency control by supplying fast frequency response. While the primary response of synchronous machines acts some seconds after the disturbance, the power electronics interfaced sources can supply a faster response. However, as mentioned in [44], this fast power injections can jeopardise system transient stability. In the case presented in this section, it is shown how those fast power injections may lead to system loss of synchronism.

The evaluated contingency in this case study is the loss of generator G5 in Fig. 10. In order to describe the phenomena, two cases are compared. In both cases, the point to point VSC-HVDC system is controlled to track constant power references.

Stable case: No fast frequency response is injected by the renewable sources after generator tripping, only the primary reserve of the generators participates on frequency control. In Figure 11a, the frequency of the COI of each region as well as the COI of the whole system are represented. It can be seen that after generator tripping the global frequency drops, and frequency of each areas oscillates around the global frequency. The system remains in synchronism and some seconds after the contingency, frequencies reach the same steady state value.

Unstable case: Fast frequency response is injected. While generator tripping occurs in zone two the fast frequency response is 


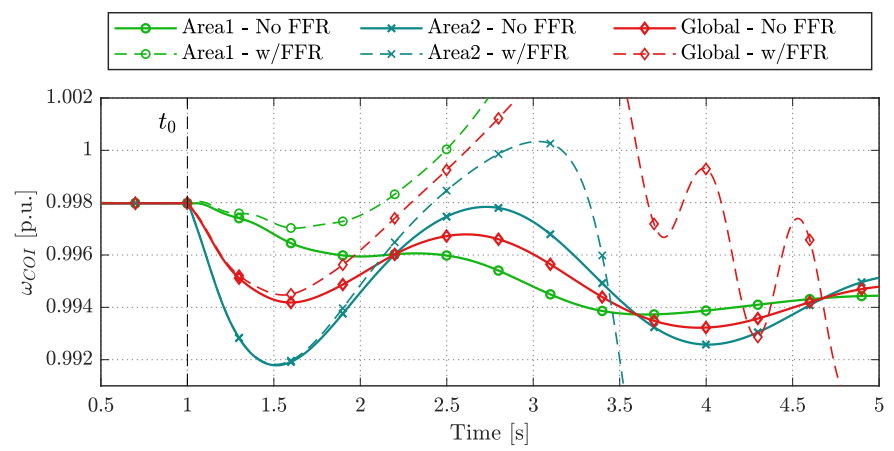

(a) Frequency of the COI of the system and both areas.

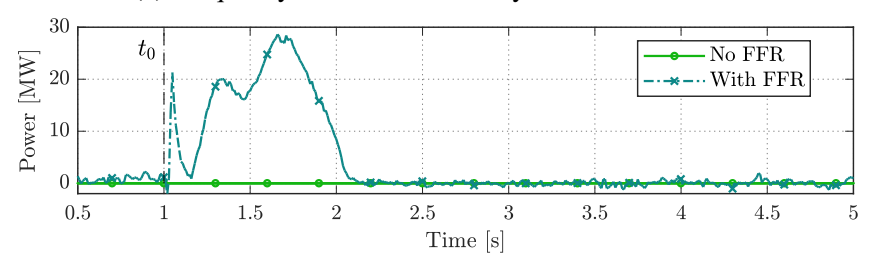

(b) Injected dynamic frequency reserve

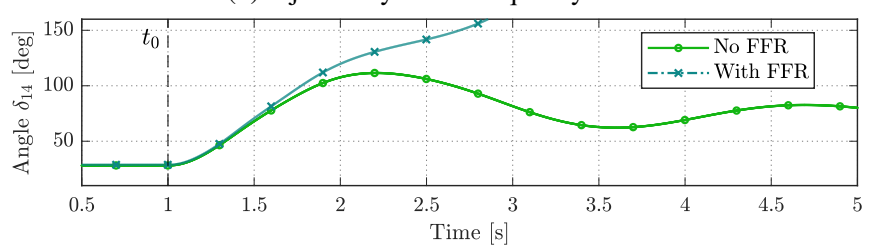

(c) Angle difference

Fig. 11: System split caused by a poorly coordinated fast frequency response.

injected in zone one, so the system will naturally transport the injected power from zone 1 to zone 2 by increasing the transport angle between regions. FFR power injections will limit the drop of the frequency on Area 1, while Area 2 has to wait the transport angle to become larger in order to receive that increase of power. As shown in Figure 11a, during the first hundred milliseconds, the FFR limits the frequency drop of Area 1 but not in Area 2, this will lead to higher frequency difference between regions, thus a transport angle beyond the stable limit and consequently to system split.

The HVDC link is a suitable mechanism to share the fast reserves while maintaining the synchronism of the system and damping power oscillations. As done before, two controllers are studied, the POD and the NFL control. Figure 12 shows the system response with different controllers. It can be observed that with both strategies, the synchronisation is assured and frequency oscillations are well damped while the FFR response is correctly delivered by the power electronic interfaced source.

Comparing those results with the system response without supplementary controllers, it is observed that the stable frequency in post-fault operation is higher than in the case where no FFR is supplied (0.996 p.u. vs 0.994 p.u.). When no FFR is injected, the minimum value of the global frequency is around 0.992 p.u. during the first swing. This minimal value is improved when controllers are implemented. Since the proposed control takes the angle difference as a feedback signal, in the equilibrium point after the disturbance, the VSC-HVDC link transmits more power than in the initial equilibrium point (250 MW vs. $200 \mathrm{MW}$ ). This means that the angle difference between regions in the post fault equilibrium point is smaller when the NFL control is implemented, so stability margins of the post-fault situation are bigger when the NFL control is implemented.

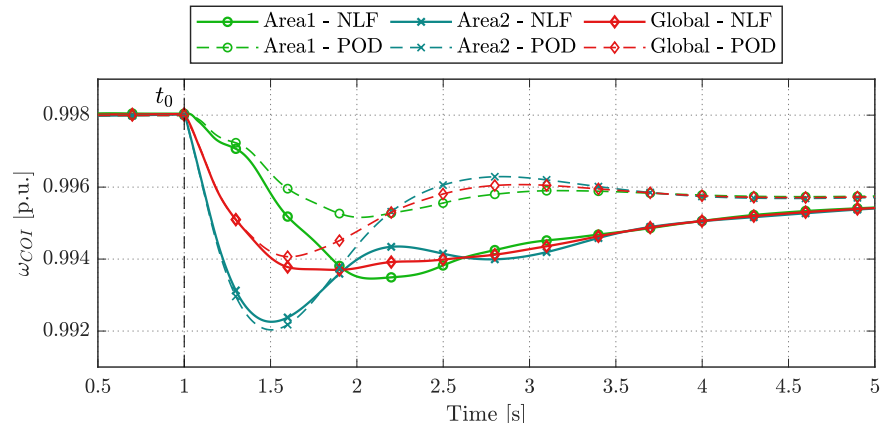

(a) Frequency of the COI of the system and both areas.

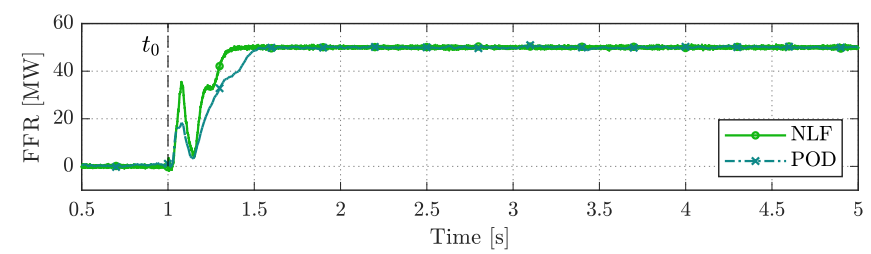

(b) Frequency Containment Reserve.

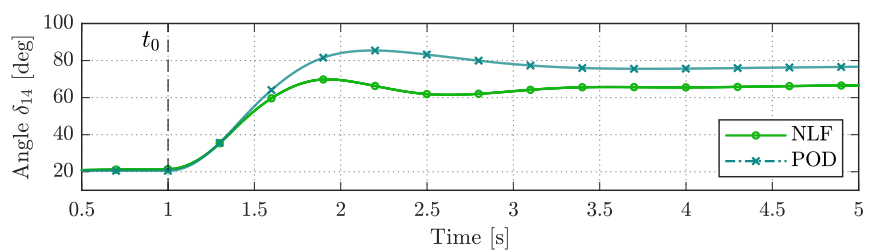

(c) Angle difference between both regions

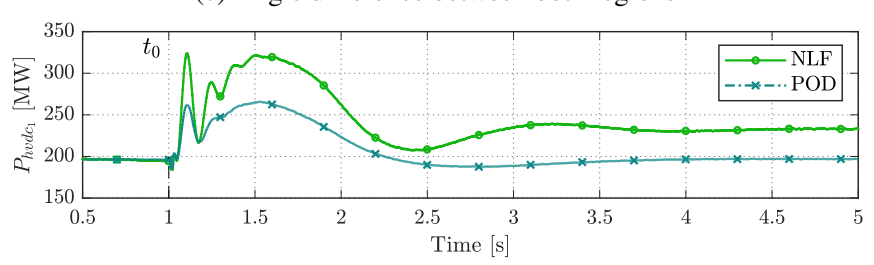

(d) Injected active power by the HVDC link

Fig. 12: Comparison of controllers when generator 5 is tripped and dynamic frequency response is applied

\subsection{Transient stability in case of DC fault}

The impact of DC faults on transient stability as well as strategies to minimise this impact, have been scarcely addressed in the literature [46]. Hence, this study case aims to show how transient stability can be jeopardise in case a fault occurs in the DC side of the transmission line. In addition, we aim to show how the modulation of active and reactive powers can be used to enhance transient stability in such cases. To do so, we can consider that a temporary pole-to-ground fault occurs on DC side of the negative pole of the first station. All stations in this case are half-bridge Modular Multilevel Converters. The protection strategy used for treating the DC fault is the Converter-Breaker strategy presented in [45]. The different steps of the protection strategy shown in Figures 14 and 13 are summarised in the following table.

Table 2 Description of the protection sequence.

\begin{tabular}{ccl}
\hline$t_{n}$ & $\mathrm{t}[\mathrm{s}]$ & Description \\
\hline$t_{0}$ & 1 & Temporary Pole-to-ground fault on negative pole \\
$t_{1}$ & 1.1 & MMC deblocking and start of STATCOM operation \\
$t_{2}$ & 1.35 & DC Line reconnection and DC voltage recovery \\
$t_{3}$ & 1.6 & Beginning of active power restoration
\end{tabular}




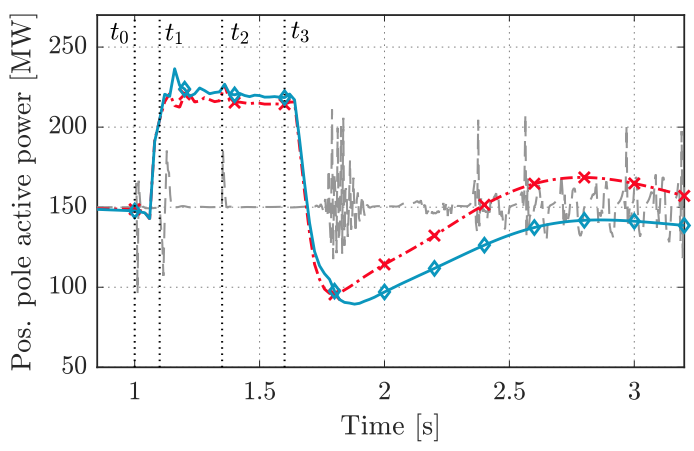

(a) Pos. pole active power

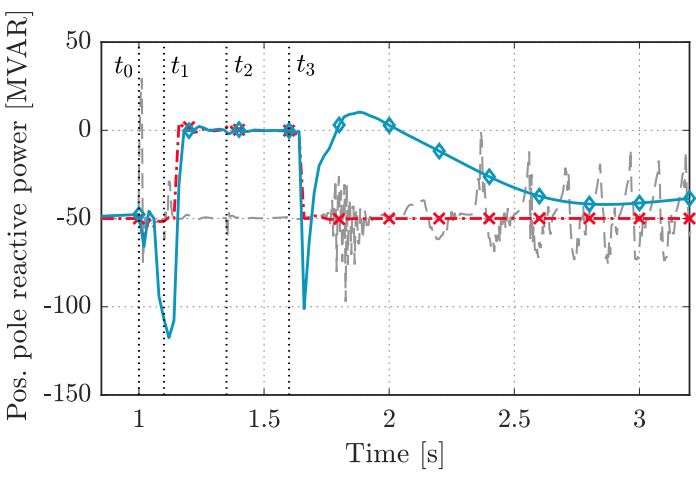

(c) Pos. pole reactive power

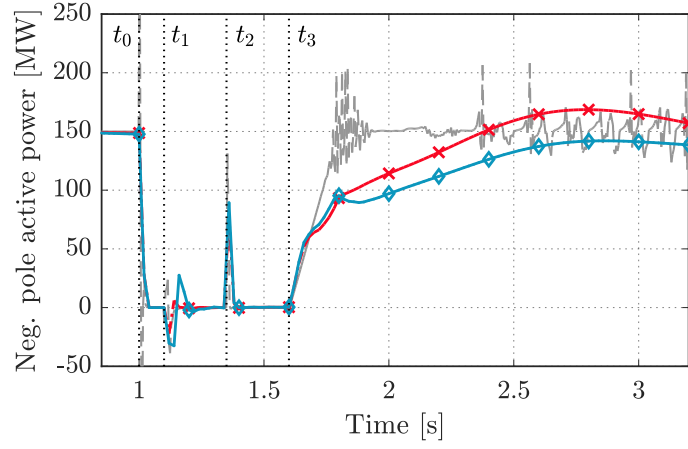

(b) Neg. pole active power

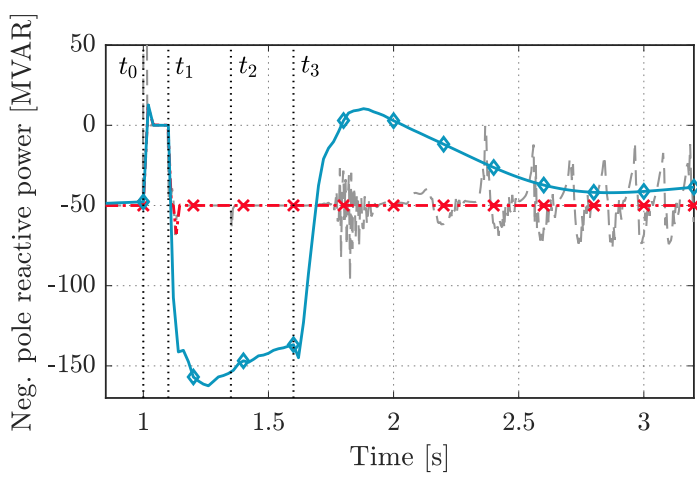

(d) Neg. pole reactive power

Fig. 13: Active and reactive power injections during execution of the converter breaker strategy triggered by a DC fault[45]

When the fault occurs $\left(t_{0}\right)$, the current flowing through the station increases until the fault is detected and the DC circuit breakers (DCCB) disconnect the faulted cable, and hence suppress the current contribution to the fault. It should be noted that after fault and before DCCB breaker opening, MMC converters are rapidly blocked and the AC contribution to the fault passes through the freewheeling diodes [47]. When the converter is blocked it exhibits the behaviour of an uncontrolled rectifier. When the faulted cable is isolated, the MMC can be deblocked $\left(t_{1}\right)$, therefore the faulted pole can operate in STATCOM mode. As it can be seen in Figure 13d, while the MMC is blocked (between $t_{0}$ and $t_{1}$ ), reactive power is zero, while after deblocking the reactive power control is recovered. Before reconnection, the overhead line requires deionization, which in this simulation lasts $350 \mathrm{~ms}\left(t_{2}\right)$ after DC circuit breaker opening [46]. After this time, the cable can be reconnected and the control of the DC voltage is recovered. Then, the system is ready to return to operation $\left(t_{3}\right)$ and power is smoothly restored to its initial value.

For this example power references are set to $300 \mathrm{MW}$ for the VSC-HVDC link and the total exchanged power between 2 regions is $500 \mathrm{MW}$. Figures 13 and 14 show the response of the DC and AC systems respectively, in case of a DC fault. Three control strategies are compare:

- Constant references: Active and reactive power references are maintained constant

- NFL- $Q_{r e f}$ constant: Active power references are modulated using the proposed non-linear feedback control

- NFL- $\Delta Q_{h v d c}$ : Reactive power injections are taken into account in the linearizing feedback law

When no supplementary control is implemented, the temporary power interruption in one pole leads to the loss of transient stability. In the case where NFL is implemented, the linearizing feedback

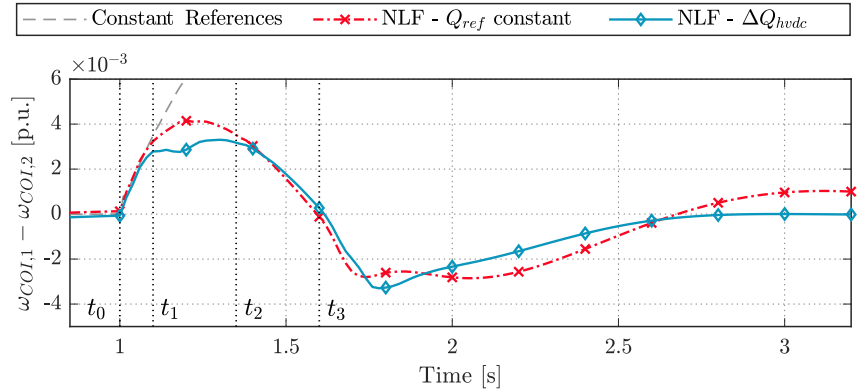

(a) Speed deviation between zones

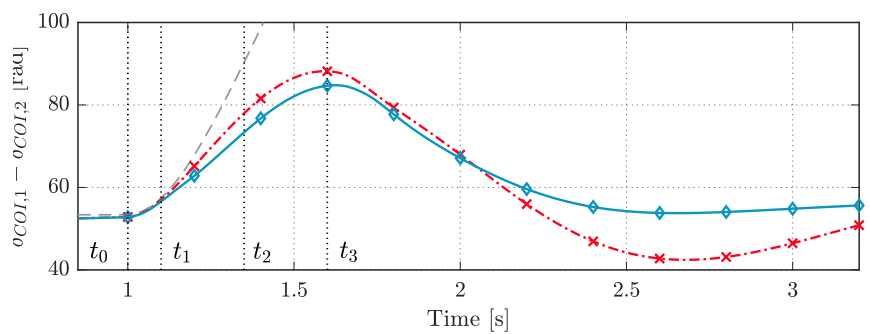

(b) Angle difference between zones

Fig. 14: AC System response after a DC fault and implementation of the converter breaker strategy [45]

action of the controller includes the information about the power references $\left(P_{h v d c 0}\right)$, thus it is possible to update the value of the static references including the loss of power of the faulted pole with 
a negligible communication delay. In the second and third case, this action compensates the lost pole with the power available in the healthy pole as it can be seen in Figure 13a. The healthy pole goes from its initial value (150MW) to its maximum power (around $220 \mathrm{MW}$ ). From the AC grid point-of-view, the power lost is only of around $80 \mathrm{MW}$. This power compensation will reduce the effect of the contingency on transient stability.

When the MMC station is deblocked after fault clearing, it is possible to work in STATCOM mode before recovering the active power injections. As shown in Equations (11) reactive power injections of the MMC stations have an impact on the active power of the synchronous machines. Therefore when the STATCOM operation begins, then reactive power injections can be used as a control input for enhancing transient stability in case of DC fault. In Figures 14 and $13 \mathrm{c}$ reactive power injections of the negative and positive poles are shown. While the healthy pole compensates the power loss (between $t_{1}$ and $t_{2}$ in Figure 13a), the inner current control gives priority to the active power injections, this is why reactive power goes to zero (Figure 13c). However, after deblocking, reactive power injections of the faulted pole can be modulated for reducing the impact of the active power loss. Figure 14b shows that angle difference between regions are slightly reduced when reactive power is modulated. The impact of reactive power injections depends on the distribution factors determined by the topological situation of the VSC-HVDC link.

\section{Conclusions}

In this article, the impact of embedded VSC-HVDC links on the surrounding AC grid is discussed and a supplementary control for stability purposes has been developed. The proposed control has been tested for different contingencies. Important conclusions should be taken from this article:

- Transient stability margins are lower when a system is reinforced with VSC-HVDC lines instead of AC lines. Indeed, VSC-HVDC links controlled to track constant power references, do not inherently improve transient stability of the surrounding AC grid as an AC line naturally does. Hence, supplementary controllers on VSC-HVDC links are needed for supporting AC transient stability.

- Through the proposition of the control, three main actions for supporting transient stability were identified: injection of synchronising power, injection of damping power and fast compensation of power disturbances.

- Synchronisation of two power grids can be achieved through the proposed control even when no AC link is interconnecting both grids.

- Poor Fast Frequency Response can destabilise the grid. Through the proposed control, the VSC-HVDC link can help the system to properly share those reserves.

- The effect of a DC fault on transient stability has been analysed. The importance of fast power reallocation as well as reactive power injections in case of a fault on the DC side of the converter has been highlighted.

\section{Acknowledgement}

This work is supported by the French Government under the program Investissements d'Avenir (ANE-ITE-002-01).

\section{References}

1 Kundur, P., Balu, N.J., Lauby, M.G.: 'Power system stability and control' (McGraw-hill New York, 1994)

2 ENTSO.E. 'ENTSO-E Draft Network Code on High Voltage Direct Current Connections and DC connected Power Park Modules'. (ENTSO-E, 2014).

3 Kundur, P., Klein, M., Rogers, G.J., Zywno, M.S.: 'Application of power system stabilizers for enhancement of overall system stability', IEEE Transactions on Power Systems, 1989, 4, (2), pp. 614-626

4 Pai, M.A.: 'Energy function analysis for power system stability'. (Boston, MA, US: Springer Science \& Business Media, 2012)
5 Machowski, J., Kacejko, P., Nogal, Ł., Wancerz, M.: 'Power system stability enhancement by WAMS-based supplementary control of multi-terminal HVDC networks', Control Engineering Practice, 2013, 21, (5), pp. 583-592

6 Padiyar, K.: 'Structure Preserving Energy Functions in Power Systems: Theory and Applications'. (Boca Raton, Fla, US: CRC Press, 2016)

7 Anderson, P.M., Fouad, A.A.: 'Power system control and stability'. (John Wiley \& Sons, 2008)

8 Elizondo, M.A., Fan, R., Kirkham, H., Ghosal, M., Wilches.Bernal, F., Schoenwald, D., et al.: 'Interarea oscillation damping control using high-voltage dc transmission: A survey', IEEE Transactions on Power Systems, 2018, 33, (6), pp. 6915-6923

9 Cresap, R.L., Mittelstadt, W.A.: 'Small-signal modulation of the Pacific HVDC intertie', IEEE Transactions on Power Apparatus and Systems, 1976, 95, (2), pp. 536-541

10 Pai, M.A., Padiyar, K.R., Radhakrishna, C.: 'Transient stability analysis of multimachine AC/DC power systems via energy-function method', IEEE Transactions on Power Apparatus and Systems, 1981, , (12), pp. 5027-5035

11 Hao, C. 'Design of modulation controller to damp power oscillations of parallel AC line in the Tianshenqiao to Guangdong HVDC transmission'. In: Proc. TENCON '93. IEEE Region 10 International Conference on Computers, Communications and Automation. vol. 5. (Beijing, China), 1993. pp. 244-247

12 Latorre, H.F., Ghandhari, M., Soder, L. 'Application of Control Lyapunov Functions to Voltage Source Converters-based High Voltage Direct Current for Improving Transient Stability'. In: Proc. 2007 IEEE Lausanne Power Tech. (Lausanne, Switzerland, . pp. 244-249

13 Latorre, H.F., Ghandhari, M., Söder, L.: 'Active and reactive power control of a VSC-HVDC', Electric Power Systems Research, 2008, 78, (10), pp. 1756-1763

14 Sigrist, L., Echavarren, F., Rouco, L., Panciatici, P. 'A fundamental study on the impact of HVDC lines on transient stability of power systems'. In: Proc. 2015 IEEE Eindhoven PowerTec. (Eindhoven, Netherlands), 2015. pp. 1-6

15 Gonzalez-Torres, J.C., Mermet-Guyennet, J., Silvant, S., Benchaib, A 'Power system stability enhancement via vsc-hvdc control using remote signals: Application on the nordic 44-bus test system'. In: 15th IET International Conference on AC and DC Power Transmission ACDC 2019. (Coventry, UK), 2019. pp. 1-6

16 Schoenwald, D.A., Pierre, B.J., Wilches.Bernal, F., Trudnowski, D.J. 'Design and implementation of a wide-area damping controller using high voltage DC modulation and synchrophasor feedback'. In: Proc. 20th IFAC World Congress. (Toulouse, France), 2017. pp. 67-72

17 Renedo, J., Garcia.Cerrada, A., Rouco, L.: 'Active power control strategies for transient stability enhancement of AC/DC grids with VSC-HVDC multi-terminal systems', IEEE Trans Power Syst, 2016, 31, (6), pp. 4595-4604

18 Henry, S., Despouys, O., Adapa, R., Barthold, L., Bayfield, C., Bell, K., et al. 'Influence of embedded HVDC transmission on system security and AC network performance'. (Paris, France): Cigré, 2013.

19 Francos, P.L., Verdugo, S.S., Álvarez, H.F., Guyomarch, S., Loncle, J. 'INELFE-Europe's first integrated onshore HVDC interconnection'. In: Proc. 2012 IEEE Power \& Energy Society General Meeting. (San Diego, CA, USA), pp. $1-8$

20 Xing, Y., Marinescu, B., Belhocine, M., Xavier, F. 'Power Oscillations Damping Controller for HVDC Inserted in Meshed AC Grids'. In: 2018 IEEE PES Innovative Smart Grid Technologies Conference Europe. (Sarajevo, Bosnia and Herzegovina), 2018. pp. 1-6

21 Aminifar, F., Fotuhi-Firuzabad, M., Safdarian, A., Davoudi, A., Shahidehpour, M. 'Synchrophasor measurement technology in power systems: Panorama and stateof-the-art', IEEE Access, 2014, 2, pp. 1607-1628

22 Fuchs, A., Imhof, M., Demiray, T., Morari, M.: 'Stabilization of large power systems using VSC-HVDC and model predictive control', IEEE Transactions on Power Delivery, 2014, 29, (1), pp. 480-488

23 Li, Y., Yang, D., Liu, F., Cao, Y., Rehtanz, C.: 'Interconnected Power Systems: Wide-Area Dynamic Monitoring and Control Applications'. (Springer Berlin Heidelberg, 2015)

24 Aouini, R., Marinescu, B., Kilani, K.B., Elleuch, M.: 'Synchronverter-based emulation and control of HVDC transmission', IEEE Transactions on Power Systems, 2016, 31, (1), pp. 278-286

25 Arioua, L., Marinescu, B.: 'Robust grid-oriented control of high voltage DC links embedded in an AC transmission system', International Journal of Robust and Nonlinear Control, 2016, 26, (9), pp. 1944-1961

26 Arioua, L., Marinescu, B.: 'Multivariable control with grid objectives of an HVDC link embedded in a large-scale AC grid', International Journal of Electrical Power \& Energy Systems, 2015, 72, pp. 99-108

27 Ghandhari, M., Andersson, G., Hiskens, I.A.: 'Control Lyapunov functions for controllable series devices', IEEE Transactions on Power Systems, 2001, 16, (4), pp. 689-694

28 Fan, X., Shu, J., Zhang, B.: 'Coordinated control of dc grid and offshore wind farms to improve rotor-angle stability', IEEE Transactions on Power Systems, 2018, 33, (4), pp. 4625-4633

29 Zama, A., Benchaib, A., Bacha, S., Frey, D., Silvant, S.: 'High dynamics control for MMC based on exact discrete-time model with experimental validation', IEEE Transactions on Power Delivery, 2018, 33, (1)

30 Chen, Y., Damm, G., Benchaib, A., Netto, M., Lamnabhi-Lagarrigue, F. 'Control induced explicit time-scale separation to attain DC voltage stability for a VSCHVDC terminal'. In: Proc. 19th IFAC World Congress. vol. 19. (CapeTown, South Africa), 2014. pp. 540-545

31 Chen, Y., Jiménez Carrizosa, M., Damm, G., Lamnabhi-Lagarrigue, F., Li, M., Li, Y.: 'Control-induced time-scale separation for multiterminal high-voltage direct current systems using droop control', IEEE Transactions on Control Systems Technology, 2020, 28, (3), pp. 967-983

32 González-Torres, I., Miranda-Vidales, H., Espinoza, J., Méndez-Barrios, C.F., González, M.: 'State feedback control assisted by a gain scheduling scheme 
for three-level NPC VSC-HVDC transmission systems', Electric Power Systems Research, 2018, 157, pp. 227-237

33 González-Torres, I., Miranda-Vidales, H., Méndez-Barrios, C.F., Espinoza, J., Cárdenas, V.: 'Long-length horizons dynamic matrix predictive control for a MMC inverter', Electric Power Systems Research, 2019, 168, pp. 137-145

34 Gonzalez-Torres, J.C., Costan, V., Damm, G., Benchaib, A., Bertinato, A., Poullain, S., et al.: 'HVDC protection criteria for transient stability of AC systems with embedded HVDC links', The Journal of Engineering, 2018

35 Chiang, H.D.: 'Direct Methods for Stability Analysis of Electric Power Systems: Theoretical Foundation, BCU Methodologies, and Applications'. (Wiley, 2010)

36 Breuer, W., Hartmann, V., Povh, D., Retzmann, D., Teltsch, E. 'Application of HVDC for large power system interconnections'. In: Proc. CIGRE Session. (Paris, France), 2004. pp. B4-106

37 Slotine, J.J.E., Li, W., et al.: 'Applied nonlinear control'. vol. 199. (Prentice hall Englewood Cliffs, NJ, 1991)

38 Khalil, H.K.: 'Nonlinear Systems'. Pearson Education. (Prentice hall Upper Saddle River, NJ, 2002)

39 Gonzalez-Torres, J.C., Costan, V., Damm, G., Benchaib, A., Lamnabhi-Lagarrigue, F., Luscan, B. 'Procédé de commande d'un lien de transmission électrique incluant une ligne haute tension continu'. (French patent), 2018. WO2019174999A1

40 Shinoda, K., Benchaib, A., Dai, J., Guillaud, X.: 'Virtual capacitor control: mitigation of DC voltage fluctuations in MMC-Based HVDC Systems', IEEE Transactions on Power Delivery, 2018, 33, (1), pp. 455-465

41 Loume, D., Tuan, M.N., Bertinato, A., Raison, B. 'DC cable modelling and High Voltage Direct Current grid grounding system'. In: Proc. 9th International Conference on Insulated Power Cables. (Versailles, Fr), 2015. pp. 1-6

42 Cui, Y., Kavasseri, R.G., Chaudhuri, N.R. 'Modeling and simulation of dynamic communication latency and data aggregation for wide-area applications'. In: Proc. 2016 Workshop on Modeling and Simulation of Cyber-Physical Energy Systems (MSCPES). (Vienna, Austria), . pp. 1-6

43 IEEE Committee Report: 'Dynamic performance characteristics of North American HVDC systems for transient and dynamic stability evaluations', IEEE Transactions on Power Apparatus and Systems, 1981, PAS-100, (7), pp. 3356-3364

44 Eriksson, R., Modig, N., Elkington, K.: 'Synthetic inertia versus fast frequency response: a definition', IET Renewable Power Generation, 2017, 12, (5), pp. 507514

45 Loume, D.S., Bertinato, A., Raison, B., Luscan, B. 'A multi-vendor protection strategy for HVDC grids based on low-speed DC circuit breakers'. In: Proc. 13th IET International Conference on AC and DC Power Transmission (ACDC 2017). (Manchester, UK), 2017. pp. 1-6

46 Tang, G., Xu, Z., Zhou, Y.: 'Impacts of three MMC-HVDC configurations on AC system stability under DC line faults', IEEE Transactions on Power Systems, 2014, 29, (6), pp. 3030-3040

47 Bertinato, A., Gonzalez-Torres, J.C., Loume, D., Creusot, C., Luscan, B. 'Development of a protection strategy for future DC networks based on low-speed DC circuit breakers'. In: Proc. CIGRE Session 2018. (Paris, France), 2018. 